\title{
MHD TURBULENT FREE CONVECTION FLUID FLOW OVER AN INFINITE VERTICAL HEAT GENERATING CYLINDER
}

\author{
Wilys O. Mukuna \\ Lecturer, Department of Mathematics and Computer Science, University of Kabianga, \\ P.O Box 2030 - 20200, KERICHO, Kenya
}

\begin{abstract}
A mathematical model of magnetohydrodynamics turbulent boundary layer fluid flow past a vertical infinite cylinder with Hall current is considered. The fluid flows along the axis of the cylinder. The fluid flow is impulsively started and the flow problem is subsequently analysed. The flow is modeled using the momentum and energy conservation equations. The Reynolds stresses arising due to turbulence in the conservation equations are resolved using Prandtl mixing length hypothesis. The equations are then solved by a finite difference method. The effects of flow parameters on the primary velocity, secondary velocity and temperature profiles are investigated. While the effect of Hall current on Primary velocity was not observed due to turbulence there was decreased secondary velocity profile when Hall parameter was increased. Primary velocity profiles increased wit increase in Grashof number and temperature profiles decreased with an increase Prandtl number.
\end{abstract}

Key words: Turbulent flow, Magnetohydrodynamics, Vertical cylinder, Free convection, Finite difference
Nomenclature
Symbol
Quantity
$j$
Current density, $A / m^{2}$
H
Magnetic fieldintensity, $\mathrm{Wb} / \mathrm{m}^{2}$
$H_{0}$
Constant magnetic fieldintensity, $\mathrm{Wb} / \mathrm{m}^{2}$
$t$
Time, $s$
E
Electricfield, $V / m$
$U_{r}, \mathrm{U}_{\theta}, \mathrm{U}_{\mathrm{x}}$
Components of velocity in the $\mathrm{r}, \theta$, and $\mathrm{x}$
axes respectively, $m / s$
$P$
Pressure of the fluid, $\mathrm{N} / \mathrm{m}^{2}$
$P_{e}$
Pressure of the fluid, $\mathrm{N} / \mathrm{m}^{2}$
$\mathrm{T}$
Absolute temperature, $K$
$C_{p}$
Specific heat at constant pressure of the fluid, $J / \mathrm{kg} / \mathrm{K}$
D
Characteristic diameter, $m$
$r^{*}, \theta^{*}, x^{*}$
Dimensional cylindrical coordinatesf the fluid,
$\omega_{e}$
electroncyclotronfrequency, $\mathrm{Hz}$
$t^{*}$
Dimensional time, $s$
$\mathrm{T}^{*}$
Dimensional temperature, $K$ 
DOI: $10.17148 /$ IARJSET.2021.8505

$\mathrm{T}_{\infty}^{*}$
$\mathrm{~T}_{w}^{*}$
$\mathrm{U}, \mathrm{V}$
$t$
$\mathrm{M}^{2}$
$\mathrm{~m}$
$\operatorname{Pr}$
$\operatorname{Pr}_{t}$
$\mathrm{Greek} \mathrm{sym}$
$\operatorname{Symbol}$
$\rho$
$\mu$
$\mu_{0}$
$\Delta t, \Delta r$
$v$
$\tau$
$\theta$
$\sigma$

$\mathrm{T}_{\infty}^{*}$

$\mathrm{T}_{w}$ t

$\mathrm{M}^{2}$

$\operatorname{Pr}$

Greek symbols

Symbol
Temperature of the fluid in the freestream, $K$

Temperature of the fluid at the plate, $K$

Dimensionless mean velocity components in $\theta$ and $r$ axes respectively,

Dimensionless time, $s$

Magnetic parameter

Hall parameter

Prandtl number

Turbulent Prandtl number

Quantity

Fluid density, $\mathrm{kg} / \mathrm{m}^{3}$

Coefficient of viscosity, $\mathrm{kg} / \mathrm{ms}$

Magnetic permeability, $\mathrm{H} / \mathrm{m}$

Time and distance intervals

Kinematic viscosity, $\mathrm{m}^{2} / \mathrm{s}$

Collision time of electron, $s$

Dimensionless fluid temperature

Electrical conductivity, $\Omega^{-1} \mathrm{~m}^{-1} s$

\section{INTRODUCTION}

Magnetohydrodynamics (MHD) is the study of the interaction between magnetic fields and moving conducting fluid [1]. MHD can be considered for both laminar and turbulent flow. Turbulent flow is characterized by a high irregular, random, fluctuating motion [8]. For practical purposes turbulent flow is considered as steady flow as long as the mean value properties do not vary with time [4] otherwise it is referred to as unsteady. Flows arising solely from the differences in density caused by temperature differences are called natural convection flows [8].

A number of numerical investigations for MHD flows have been done. A numerical investigation of magnetic effect on forced convection around two dimensional circular cylinder embedded in porous media was carried out by Ghadi et al [2]. In their work they extended governing equations in polar coordinate system for porous media. The range of Reynolds number and Peclet number was taken to be between 1 and 40. Magnetic Parameter M in their work varied between 1 and 10. They observed that the maximum amount of the local Nusselt number increases with increasing Reynolds number and that the mean Nusselt number decreases with any increase in Darcy number.

Rhoads et al, [6] investigated the effect of magnetic field on the turbulent wake of a cylinder in free-surface magnetohydrodynamic channel flow. They carried out an MHD flow experiment detailing the modification of vortices in the wake of a circular cylinder with its axis parallel to the applied magnetic field. From the results they concluded that the reduction in effective viscosity was due to the surpression of small scale eddies by the magnetic field.

A mathematical model of hydromagnetic turbulent boundary layer fluid flow past a horizontal infinite cylinder with Hall current was presented by Mukuna et. al. [5]. In the theoretical experiment the fluid flow was started impulsively and the flow problem analyzed. The governing equations that arose from the laws of conservation of momentum energy 


\section{International Advanced Research Journal in Science, Engineering and Technology}

Vol. 8, Issue 5, May 2021

\section{DOI: 10.17148/IARJSET.2021.8505}

and concentrartion were solved by finite difference method. They found that velocity profiles increase with increase in Hall parameter and temperature profiles increased with increase in magnetic parameter.

Vinuesa et al [9] did a direct numerical simulation of the flow around a wall-mounted square cylinder under various inflow conditions. They assessed the effect of inflow conditions by considering two different cases, fully turbulent zero pressure gradient boundary layer and laminar boundary layer with prescribed Blasius inflow further upstream. By this work they highlighted the usefulness of direct numerical simulation to asses the quality of experimental inflow conditions.

Magnetic field effect on the cooling of a low-Prandtl number fluid in a vertical cylinder was investigated by Sarris $e t a l$, [7]. In their work they carried out direct numerical simulations for the transient and turbulent natural convection cooling of an initially isothermal quiescent liquid metal placed in a vertical cylinder in the presence of a vertical magnetic field. The numerical results showed that the magnetic field had no observable effect at the initial stage of the vertical boundary layer development and conduction heat transfer was favored during the transition stage.

Yoon et al [10] reported on a numerical study on the fluid flow and heat transfer around a circular cylinder in an aligned magnetic field. In the study they numerically investigated two-dimensional laminar fluid flow and heat transfer past a circular cylinder in an aligned magnetic field using the spectral method. They observed that as the intensity of applied magnetic fields increased, the vortex shedding formed in the wake became weaker and the oscillating amplitude of lift coefficient decreased.

In the current investigation a study is carried out on turbulent fluid flow over an infinite vertical infinite heat generating cylinder in the presence of a strong magnetic field.

\section{MATHEMATICAL FORMULATION}

A two dimensional turbulent boundary layer flow is considered. The fluid flow is along a vertical infinitely long cylinder lying in the $x-y$ plane. The cylinder is immersed in the fluid. The axis of the cylinder is in the positive $x$-axis direction and the fluid flows upwards positive $\mathrm{x}$-axis direction parallel to the axis of the cylinder. The cylinder is assumed to have non-end effects. The fluid is assumed incompressible and viscous. A strong magnetic field of uniform strength $\mathrm{H}_{0}$ is applied along the $\mathrm{x}$-axis. The induced magnetic field is considered negligible hence $\mathbf{H}=\left(0,0, \mathrm{H}_{0}\right)$. The temperature of the surface of the cylinder and the fluid are assumed to be the same initially. At time $t^{*}>0$ the fluid starts moving impulsively with velocity $\mathrm{U}_{0}$ and at the same time the temperature of the cylinder is instantaneously raised to $T_{W}^{*}$ which is maintained constant later on. Given that the flow is over a cylinder, cylindrical coordinate form of the governing equations are used. The flow is considered to be along the axial and angular components. There is no radial flow. Thus the two dimensions of this flow are $\mathrm{x}$ and $\theta$. 
DOI: $10.17148 /$ IARJSET.2021.8505

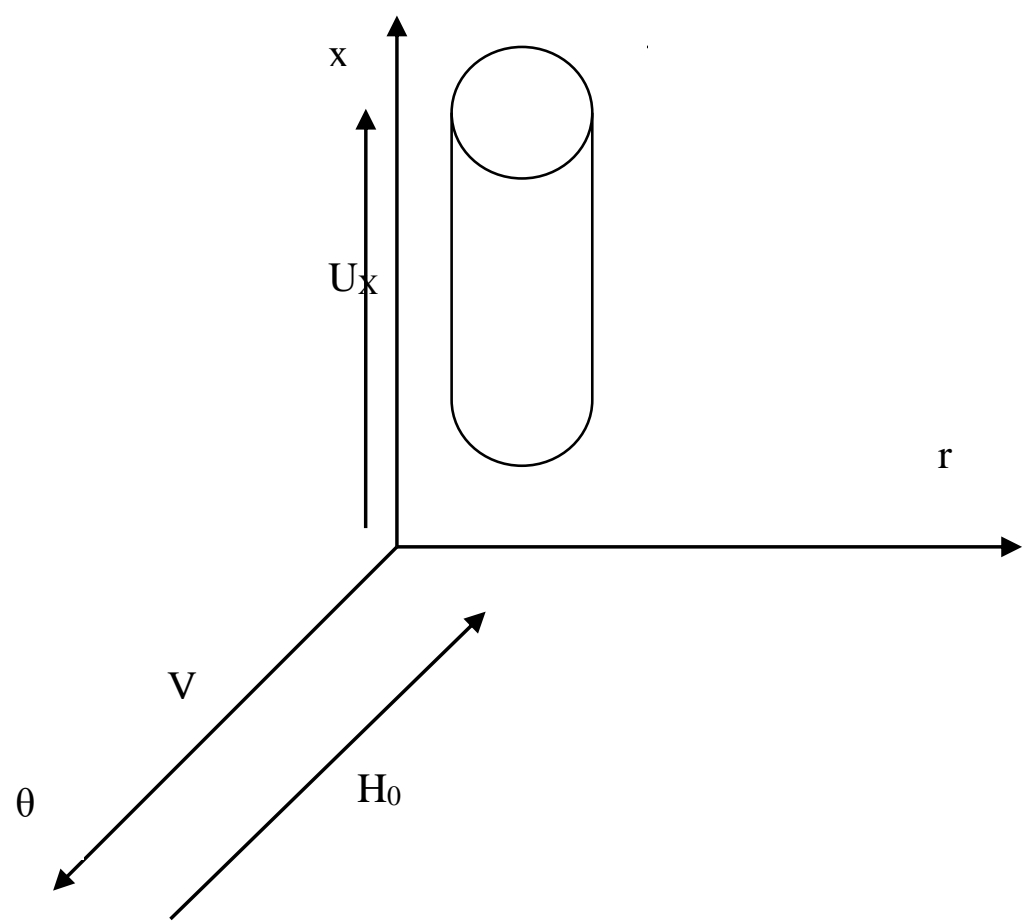

Figure 1: Geometry of the problem

The above flow is governed by the following cylindrical coordinate equations:

$$
\begin{aligned}
& \frac{\partial \bar{U}_{x}}{\partial t}=-\frac{1}{\rho} \frac{\partial \bar{P}}{\partial x}+v\left(\frac{\partial^{2} U_{x}}{\partial r^{2}}+\frac{1}{r} \frac{\partial U_{x}}{\partial r}\right)-\left[\frac{1}{r} \frac{\partial \overline{U_{x}^{\prime} U_{r}^{\prime}}}{\partial r}\right]+\rho g+\vec{J} \times\left. B\right|_{x} \\
& \frac{\partial \overline{U_{\theta}^{*}}}{\partial t^{*}}=v\left(\frac{\partial^{2} \overline{U_{\theta}^{*}}}{\partial r^{* 2}}+\frac{1}{r^{*}} \frac{\partial \overline{U_{\theta}^{*}}}{\partial r^{*}}-\frac{\overline{U_{\theta}^{*}}}{r^{* 2}}\right)-\left[\frac{\partial \overline{U_{r}^{\prime} U_{\theta}^{\prime}}}{\partial r^{*}}-\frac{2 \overline{U_{\theta}^{\prime} U_{r}^{\prime}}}{r^{*}}\right]+\vec{J} \times\left. B\right|_{\theta} \\
& \rho C_{p}\left(\frac{\partial \bar{T}^{*}}{\partial t^{*}}\right)=k\left(\frac{\partial^{2} \overline{T^{*}}}{\partial r^{* 2}}+\frac{1}{r^{*}} \frac{\partial \overline{T^{*}}}{\partial r^{*}}\right)-\rho C_{p}\left(\frac{\left.\partial \overline{U_{r}^{\prime} T^{\prime}}\right)}{\partial r^{*}}\right)
\end{aligned}
$$

It was noted that there was no pressure gradient in $\theta$ - direction and there is no gravitational force also. The boundary and initial conditions are:

$t^{*}<0: U_{x}^{*}=0, U_{\theta}^{*}=0, T^{*}=T_{\infty}^{*}$, everywhere

$t^{*} \geq 0: U_{x}^{*}=U_{0}, U_{\theta}^{*}=0, T^{*}=T_{W}^{*}$, at $r^{*}=\frac{D}{2}$ (D is the diameter of the cylinder.)

$U_{x}^{*} \rightarrow 0, U_{\theta}^{*} \rightarrow 0, T^{*} \rightarrow T_{\infty}^{*}$, as $r^{*} \rightarrow \infty$

The pressure gradient in the $\mathrm{x}$-axis direction results from the change in elevation up the cylinder. Thus:

$$
\frac{\partial P}{\partial x}=-\rho_{\infty} g
$$

Hence equation (1) becomes:

$\rho \frac{\partial \bar{U}_{x}}{\partial t}=\left(\rho_{\infty}-\rho\right) g+\mu\left(\frac{\partial^{2} U_{x}}{\partial r^{2}}+\frac{1}{r} \frac{\partial U_{x}}{\partial r}\right)-\rho\left[\frac{1}{r} \frac{\partial \overline{U_{x}^{\prime} U_{r}^{\prime}}}{\partial r}\right]+\vec{J} \times\left. B\right|_{x}$ 


\section{International Advanced Research Journal in Science, Engineering and Technology}

Vol. 8, Issue 5, May 2021

DOI: $10.17148 /$ IARJSET.2021.8505

The density difference $\rho$ - $\rho_{\infty}$ may be expressed in terms of the volume coefficient of expansion $\beta$ defined by:

$$
\beta=\frac{1}{V}\left(\frac{\partial V}{\partial T}\right)_{P}=\frac{1}{V_{\infty}} \cdot \frac{V-V_{\infty}}{T-T_{\infty}}=\frac{\rho_{\infty}-\rho}{\rho\left(T-T_{\infty}\right)}
$$

Such that (7) becomes

$$
\rho \frac{\partial \bar{U}_{x}}{\partial t}=\rho \beta g\left(T-T_{\infty}\right)+\mu\left(\frac{\partial^{2} U_{x}}{\partial r^{2}}+\frac{1}{r} \frac{\partial U_{x}}{\partial r}\right)-\rho\left[\frac{1}{r} \frac{\partial \overline{U_{x}^{\prime} U_{r}^{\prime}}}{\partial r}\right]+\vec{J} \times\left. B\right|_{x}
$$

Which simplifies to

$$
\frac{\partial \bar{U}_{x}}{\partial t}=\beta g\left(T-T_{\infty}\right)+v\left(\frac{\partial^{2} U_{x}}{\partial r^{2}}+\frac{1}{r} \frac{\partial U_{x}}{\partial r}\right)-\left[\frac{1}{r} \frac{\partial \overline{U_{x}^{\prime} U_{r}^{\prime}}}{\partial r}\right]+\vec{J} \times\left. B\right|_{x}
$$

Using (*) to indicate dimension, equation (9) becomes.

$$
\frac{\partial \overline{U_{x}^{*}}}{\partial t^{*}}=\beta g\left(T^{*}-T_{\infty}^{*}\right)+v\left(\frac{\partial^{2} \overline{U_{x x}^{*}}}{\partial r^{* 2}}+\frac{1}{r^{*}} \frac{\partial \overline{U_{x}^{*}}}{\partial r^{*}}\right)-\left[\frac{1}{r^{*}} \frac{\partial \overline{U_{x}^{\prime} U^{\prime}}}{\partial r^{*}}\right]+\vec{J} \times\left. B\right|_{x}
$$

Next, we seek to establish the components of the electromagnetic force term in (10) and (2) that is the term: $\vec{J} \times \vec{B}$

The equation of conservation of charge $\nabla . J=0$, gives $j_{r}=k$, a constant, where $\vec{J}=\left(j_{r}, j_{\theta}, j_{z}\right)$. The constant is zero since, $j_{r}=0$ at the cylinder which is insulated. Thus $j_{r}=0$ everywhere in the flow. Neglecting the ion-slip and thermoelectric effects, generalized Ohm's law including the effects of Hall current gives:

$$
\vec{J}+\frac{w_{e} \tau_{e}}{H_{0}}(\vec{J} \times \vec{H})=\sigma\left(\vec{E}+\mu_{0} \vec{q} \times \vec{H}+\frac{1}{e_{e}} \nabla P_{e}\right)
$$

For the problem we seek to solve there is no applied electric field hence $\vec{E}=0$ and thus neglecting electron pressure, equation (11) becomes:

$$
\vec{J}+\frac{w_{e} \tau_{e}}{H_{0}}(\vec{J} \times \vec{H})=\sigma \mu_{0}(\vec{q} \times \vec{H})
$$

Given that $\vec{H}=\left(H_{0}, 0,0\right)$ and taking $\vec{J}=\left(0, j_{\theta}, j_{x}\right), \vec{q}=\left(0, U_{\theta}, U_{x}\right)$ and $\vec{B}=\mu_{0} \vec{H}$ simplifying equation (12) and solving gives:

$j_{r}=0$

$j_{\theta}=\frac{\sigma \mu_{0} H_{0}\left(U_{z}+m U_{\theta}\right)}{1+m^{2}}$

$j_{z}=\frac{\sigma \mu_{0} H_{0}\left(m U_{z}-U_{\theta}\right)}{1+m^{2}}$

Where $m=w_{e} \tau_{e}$ is the Hall parameter.

Thus the electromagnetic force along $\theta$ and $\mathrm{x}$-axis are respectively:

$$
\begin{aligned}
& (J \times B)_{\theta}=\frac{\sigma \mu_{0}^{2} H_{0}^{2}\left(m U_{z}-U_{\theta}\right)}{1+m^{2}} \\
& (J \times B)_{x}=\frac{-\sigma \mu_{0}^{2} H_{0}^{2}\left(U_{z}+m U_{\theta}\right)}{1+m^{2}}
\end{aligned}
$$

Hence the governing equations (10) and (2) are respectively: 


$$
\begin{aligned}
\frac{\partial \overline{U_{x}^{*}}}{\partial t^{*}} & =v\left(\frac{\partial^{2} \overline{U_{x x}^{*}}}{\partial r^{* 2}}+\frac{1}{r^{*}} \frac{\partial \overline{U_{x}^{*}}}{\partial r^{*}}\right)-\left[\frac{1}{r^{*}} \frac{\partial \overline{U_{x}^{\prime} U_{r}^{\prime}}}{\partial r^{*}}\right]+\beta g\left(T^{*}-T_{\infty}^{*}\right)-\frac{\sigma \mu_{0}^{2} H_{0}^{2}\left(\overline{U_{x}^{*}}+m \overline{U_{\theta}^{*}}\right)}{1+m^{2}} \\
\frac{\partial \overline{U_{\theta}^{*}}}{\partial t^{*}} & =v\left(\frac{\partial^{2} \overline{U_{\theta}^{*}}}{\partial r^{* 2}}+\frac{1}{r^{*}} \frac{\partial \overline{U_{\theta}^{*}}}{\partial r^{*}}-\frac{\overline{U_{\theta}^{*}}}{r^{* 2}}\right)-\left[\frac{\partial \overline{U_{r}^{\prime} U_{\theta}^{\prime}}}{\partial r^{*}}-\frac{2 \overline{U_{\theta}^{\prime} U_{r}^{\prime}}}{r^{*}}\right]+\frac{\sigma \mu_{0}^{2} H_{0}^{2}\left(m \overline{U_{x}^{*}}-\overline{U_{\theta}^{*}}\right)}{1+m^{2}}
\end{aligned}
$$

\subsection{Non-Dimensionalization}

We seek to non-dimensionalize equations (3), (18) and (19). The following scaling variables are applied in the nondimensionalization process:

$t=\frac{t^{*} U_{0}^{2}}{v} ; r=\frac{r^{*} U_{0}}{v} ; U_{i}=\frac{U_{i}^{*}}{U_{0}} ; \theta=\frac{T^{*}-T_{\infty}^{*}}{T_{w}^{*}-T_{\infty}^{*}}$

The $(*)$ superscript denotes the dimensional variables, Uo is the reference velocity, D is the diameter of the cylinder, $\mathrm{T}^{*}{ }_{\mathrm{w}}-\mathrm{T}^{*}{ }_{\infty}$ is the temperature difference between the surface and the free stream temperature.

Using the scaling variables above yields the following equations:

$$
\begin{aligned}
& \frac{\partial U_{x}}{\partial t}=\left(\frac{\partial^{2} U_{x}}{\partial r^{2}}+\frac{1}{r} \frac{\partial U_{x}}{\partial r}\right)-\left[\frac{1}{r} \frac{\partial \overline{U_{x}^{\prime} U_{r}^{\prime}}}{\partial r}\right]+G r \theta-M^{2} \frac{\left(U_{x}+m U_{\theta}\right)}{\left(1+m^{2}\right)} \\
& \frac{\partial U_{\theta}}{\partial t}=\left(\frac{\partial^{2} U_{\theta}}{\partial r^{2}}+\frac{1}{r} \frac{\partial U_{\theta}}{\partial r}-\frac{U_{\theta}}{r^{2}}\right)-\left[\frac{\partial \overline{U_{x}^{\prime} U_{r}^{\prime}}}{\partial r}-\frac{2 \overline{U_{\theta}^{\prime} U_{r}^{\prime}}}{r}\right]+M^{2} \frac{\left(m U_{x}-U_{\theta}\right)}{\left(1+m^{2}\right)} \\
& \frac{\partial \theta}{\partial t}=\frac{1}{\operatorname{Pr}}\left(\frac{\partial^{2} \theta}{\partial r^{2}}+\frac{1}{r} \frac{\partial \theta}{\partial r}\right)-\frac{\partial\left(\overline{U_{r}^{\prime \prime} \theta^{\prime}}\right)}{\partial r}
\end{aligned}
$$

Where:

$$
\begin{aligned}
& G r=v g \beta \frac{T_{w}^{*}-T_{\infty}^{*}}{U_{0}^{3}} \\
& \operatorname{Pr}=\mu \mathrm{C}_{\mathrm{p}} / \mathrm{k} \\
& M^{2}=\frac{\sigma \mu_{0}^{2} H_{0}^{2} v}{U_{0}^{2}}
\end{aligned}
$$

\subsection{Boundary and Initial Conditions}

From equation (20) the non-dimensional form of (5) becomes:

$t<0: U_{x}=0, U_{\theta}=0, \theta=0$ everywhere

$t \geq 0: U_{x}=1, U_{\theta}=0, \theta=1$ at $r=\frac{1}{2}$

$U_{x} \rightarrow 0, U_{\theta} \rightarrow 0, \theta \rightarrow 0$ as $r \rightarrow \infty$

\subsection{Prandtl Mixing Length Hypothesis}

We need to solve equations (21), (22) and (23), subject to equations (24), (25) and (26). However the solution of these equations is not currently possible due to the Reynolds stress terms. We thus resolve these terms first, for us to be able to work out the approximate solution of these equations by a direct numerical method. The momentum equations are resolved using Prandtl mixing length hypothesis. The Reynolds stresses in the energy conservation equation are 


\section{International Advanced Research Journal in Science, Engineering and Technology}

Vol. 8, Issue 5, May 2021

\section{DOI: 10.17148/IARJSET.2021.8505}

computed in terms of Turbulent Prandtl number and Prandtl mixing length hypothesis. Thus equations (21) - (26) become:

$$
\begin{aligned}
& \frac{\partial U_{x}}{\partial t}=\left(\frac{\partial^{2} U_{x}}{\partial r^{2}}+\frac{1}{r} \frac{\partial U_{x}}{\partial r}\right)+k^{2} r\left(\frac{\partial U_{x}}{\partial r}\right)\left(\frac{\partial U_{x}}{\partial r}\right)+G r \theta-M^{2} \frac{\left(U_{x}+m_{\theta}\right)}{\left(1+m^{2}\right)} \\
& \frac{\partial U_{\theta}}{\partial t}=\left(\frac{\partial^{2} U_{\theta}}{\partial r^{2}}+\frac{1}{r} \frac{\partial U_{\theta}}{\partial r}-\frac{U_{\theta}}{r^{2}}\right)+2 k^{2} r^{2}\left(\frac{\partial U_{\theta}}{\partial r}\right)\left(\frac{\partial^{2} U_{\theta}}{\partial r^{2}}\right)+M^{2} \frac{\left(m U_{x}-U_{\theta}\right)}{\left(1+m^{2}\right)} \\
& \frac{\partial \theta}{\partial t}=\frac{1}{\operatorname{Pr}}\left(\frac{\partial^{2} \theta}{\partial r^{2}}+\frac{1}{r} \frac{\partial \theta}{\partial r}\right)+\frac{k^{2} r^{2}}{\operatorname{Pr}_{t}}\left(\frac{\partial U_{x}}{\partial r}\right)\left(\frac{\partial \theta}{\partial r}\right)
\end{aligned}
$$

$t<0: U_{x}=0, U_{\theta}=0, \theta=0$, everywhere

$t \geq 0: U_{x}=1, U_{\theta}=0, \theta=1$, at $r=\frac{1}{2}$

$U_{x} \rightarrow 0, U_{\theta} \rightarrow 0, \theta \rightarrow 0$, as $r \rightarrow \infty$

\subsection{Finite Difference Scheme}

Considering that the systems of partial differential equations (27) - (29) are highly non-linear their solutions are approximated by finite difference method. In the following finite difference scheme the primary velocity $U_{x}$ is denoted by $\mathrm{U}$ and the secondary velocity $\mathrm{U}_{\theta}$ is denoted by $\mathrm{V}$ to reduce the subscripts as $\mathrm{i}$ and $\mathrm{j}$ are used as subscripts, $\mathrm{i}$ corresponding to $\mathrm{r}$ as $\mathrm{j}$ corresponds to $\mathrm{t}$. The equivalent finite difference scheme for equations are respectively:

Where $\mathrm{i}$ and $\mathrm{j}$ refer to $\mathrm{r}$ and $\mathrm{t}$ respectively. $\mathrm{r}$ have been substituted with $i \Delta r$

$$
\begin{gathered}
U_{(i, j+1)}=U_{(i, j)}+\Delta t\left(\frac{U_{(i+1, j)}-2 U_{(i, j)}+U_{(i-1, j)}}{(\Delta r)^{2}}+\frac{1}{i \Delta r} \frac{U_{(i+1, j)}-U_{(i, j)}}{\Delta r}\right)+ \\
k^{2} i(\Delta r)(\Delta t)\left(\frac{\left.U_{(i+1, j)}-U_{(i, j)}\right)^{2}}{\Delta r}+\Delta t\left\{G r \theta_{(i, j)}-M^{2} \frac{\left(U_{(i, j)}+m V_{(i, j)}\right)}{1+m^{2}}\right\} \ldots \ldots \ldots . . .\right. \\
V_{(i, j+1)}=V_{(i, j)}+\Delta t\left(\frac{V_{(i+1, j)}-2 V_{(i, j)}+V_{(i-1, j)}}{(\Delta r)^{2}}+\frac{1}{i \Delta r} \frac{V_{(i+1, j)}-V_{(i, j)}}{\Delta r}-\frac{V_{(i, j)}}{(i \Delta r)^{2}}\right)+ \\
2 k^{2}(i \Delta r)^{2}(\Delta t)\left(\frac{\left.V_{(i+1, j)}-V_{(i, j)}\right)}{\Delta r}\right)\left(\frac{V_{(i+1, j)}-2 V_{(i, j)}+V_{(i-1, j)}}{(\Delta r)^{2}}\right)+\Delta t M^{2} \frac{\left(m U_{(i, j)}-V_{(i, j)}\right)}{1+m^{2}} \\
\theta_{(i, j+1)}=\theta_{(i, j)}+\frac{\Delta t}{\operatorname{Pr}}\left(\frac{\theta_{(i+1, j)}-2 \theta_{(i, j)}+\theta_{(i-1, j)}}{(\Delta r)^{2}}+\frac{1}{i \Delta r} \frac{\theta_{(i+1, j)}-\theta_{(i, j)}}{\Delta r}\right)+ \\
\frac{k^{2}(\Delta t)(i \Delta r)^{2}}{\operatorname{Pr}_{t}}\left(\frac{U_{(i+1, j)}-U_{(i, j)}}{\Delta r}\right)\left(\frac{\theta_{(i+1, j)}-\theta_{(i, j)}}{\Delta r}\right)
\end{gathered}
$$

The boundary and initial conditions take the form:

$j<0: U_{(i, j)}=0, V_{(i, j)}=0, \theta_{(i, j)}=0$, everywhere

$j \geq 0: U_{(i, j)}=1, V(i, j)=0, \theta_{(i, j)}=1$, at $i=\frac{\operatorname{Re}}{2}$ 
$U_{(i, j)} \rightarrow 0, V_{(i, j)} \rightarrow 0, \theta_{(i, j)} \rightarrow 0$, as $i \rightarrow \infty$

Using the boundary and initial conditions we determine the values for consecutive grid points for primary velocity, secondary velocities, and temperature that is $U_{(i, j+1)}, V_{(i, j+1)}$ and $\theta_{(i, j+1)}$ in component form.

The approximate solution was computed using a computer programme and the results are displayed in graphs as shown in figures 2,3 and 4.

\section{DISCUSSION OF RESULTS}

The cooling of the plate takes place when the Grashof number is greater than zero $\left(\mathrm{Gr}=1 \times 10^{4}\right)$. In this case the cylinder is at a higher temperature than the surrounding leading to cooling of the cylinder by free convection currents.

\subsection{PRIMARY VELOCITY PROFILES}

From figure 2 it is noted that:

(i) Primary velocity is not affected by magnetic parameter and Hall parameter.

(ii) There is an increase in primary velocity profiles when Grashof number and time parameter are increased.

(iii) There is no change in primary velocity when Prandtl number is varied.

\subsection{SECONDARY VELOCITY PROFILES}

From figure 3 it is noted that:

(i) The secondary velocity profiles increase in magnitude with increase in time parameter and magnetic parameter.

(ii) Variation in Grashof number does not affect secondary velocity profiles

(iii) There is no variation in velocity profiles with variation in Prandtl.

(iv) There is decrease in the secondary velocity profiles with increase in Hall parameter.

\subsection{TEMPERATURE PROFILES}

From figure 4 it is noted that:

(i) There is no observable variation in temperature profiles with variation in magnetic parameter and Hall parameter.

(ii) There is increase in temperature profiles with increase in time parameter.

(iii) There is decrease in temperature profiles with increase in Grashof number.

(iv) Increase in Prandtl number leads to decrease in temperature profiles. 
International Advanced Research Journal in Science, Engineering and Technology

Vol. 8, Issue 5, May 2021

DOI: $10.17148 /$ IARJSET.2021.8505

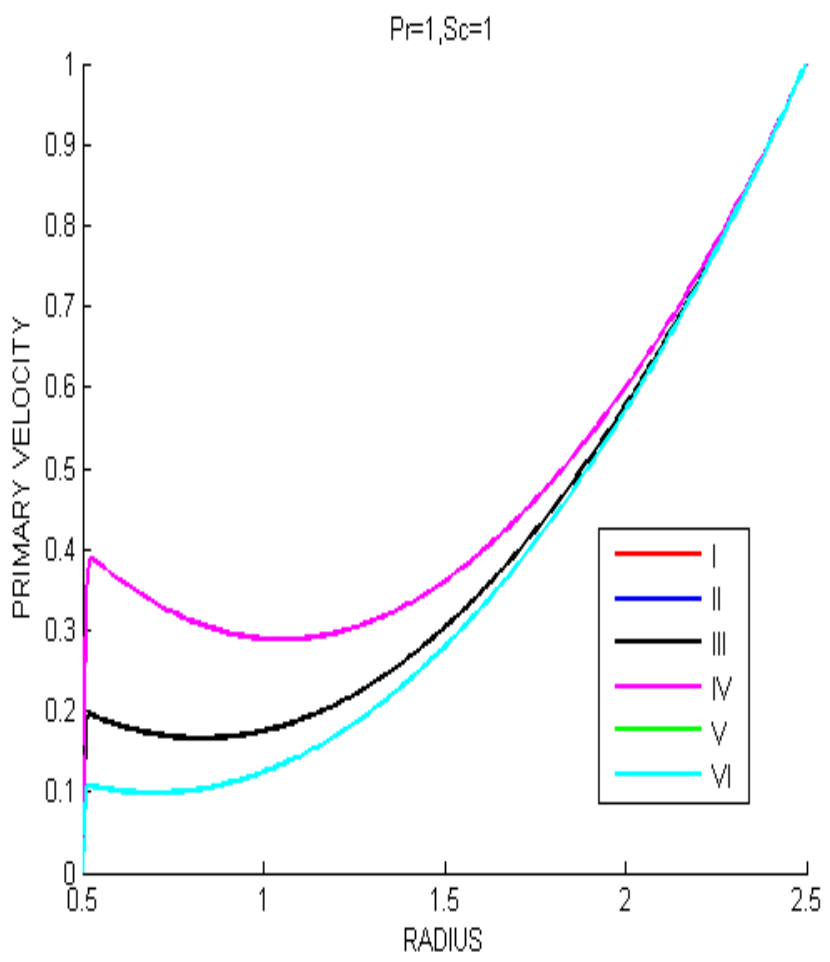

\begin{tabular}{|l|l|l|l|l|}
\hline & $\mathrm{M}^{2}$ & $\mathrm{~m}$ & $\mathrm{t}$ & $\mathrm{Gr}$ \\
\hline $\mathrm{I}$ & 2 & 2 & 0.2 & $1.0 \mathrm{E} 4$ \\
\hline $\mathrm{II}$ & 4 & 2 & 0.2 & $1.0 \mathrm{E} 4$ \\
\hline $\mathrm{III}$ & 2 & 4 & 0.2 & $1.0 \mathrm{E} 4$ \\
\hline $\mathrm{IV}$ & 2 & 2 & 0.4 & $1.0 \mathrm{E} 4$ \\
\hline $\mathrm{V}$ & 2 & 2 & 0.2 & $1.0 \mathrm{E} 3$ \\
\hline $\mathrm{VI}$ & 2 & 2 & 0.2 & $1.0 \mathrm{E} 4$ \\
\hline
\end{tabular}

Figure 2 Primary velocity profiles with cooling of the cylinder

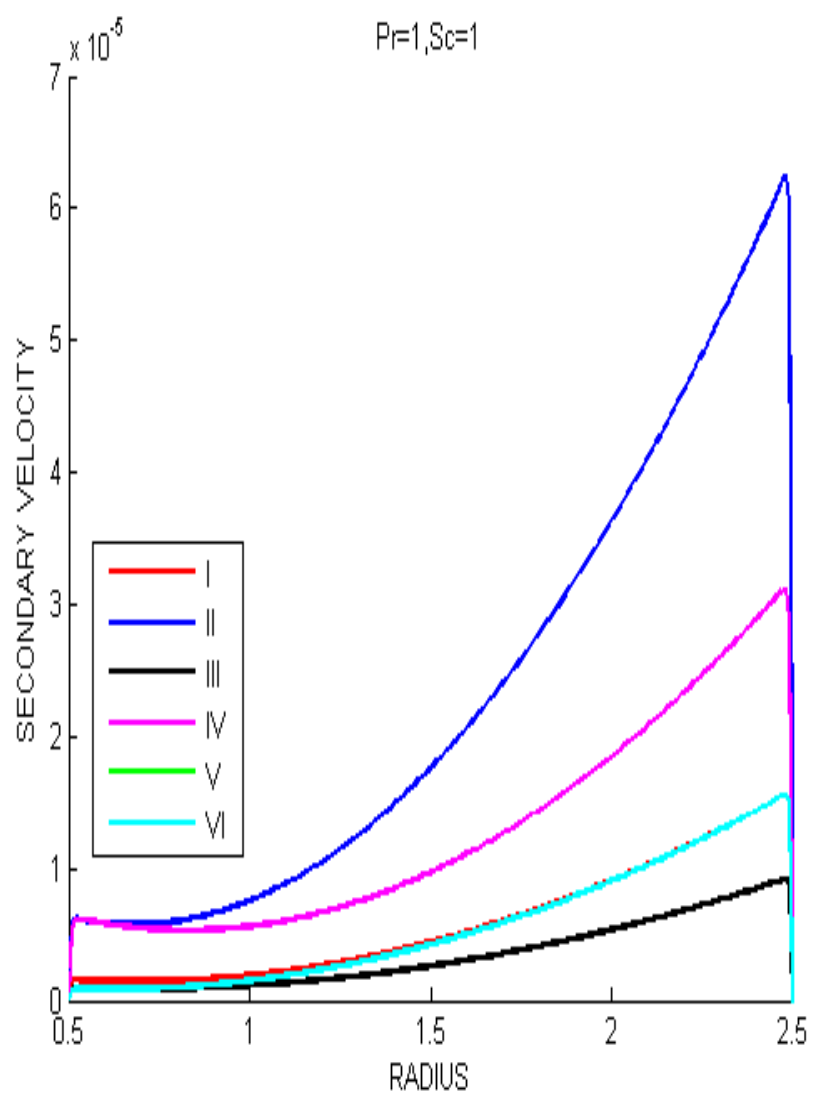

\begin{tabular}{|l|l|l|l|l|}
\hline & $\mathrm{M}^{2}$ & $\mathrm{~m}$ & $\mathrm{t}$ & $\mathrm{Gr}$ \\
\hline $\mathrm{I}$ & 2 & 2 & 0.2 & $1.0 \mathrm{E} 4$ \\
\hline $\mathrm{II}$ & 4 & 2 & 0.2 & $1.0 \mathrm{E} 4$ \\
\hline $\mathrm{III}$ & 2 & 4 & 0.2 & $1.0 \mathrm{E} 4$ \\
\hline $\mathrm{IV}$ & 2 & 2 & 0.4 & $1.0 \mathrm{E} 4$ \\
\hline V & 2 & 2 & 0.2 & $1.0 \mathrm{E} 3$ \\
\hline $\mathrm{VI}$ & 2 & 2 & 0.2 & $1.0 \mathrm{E} 4$ \\
\hline
\end{tabular}

Figure 3 Secondary velocity profiles with cooling of the cylinder 


\section{International Advanced Research Journal in Science, Engineering and Technology}

Vol. 8, Issue 5, May 2021

DOI: $10.17148 / I A R J S E T .2021 .8505$

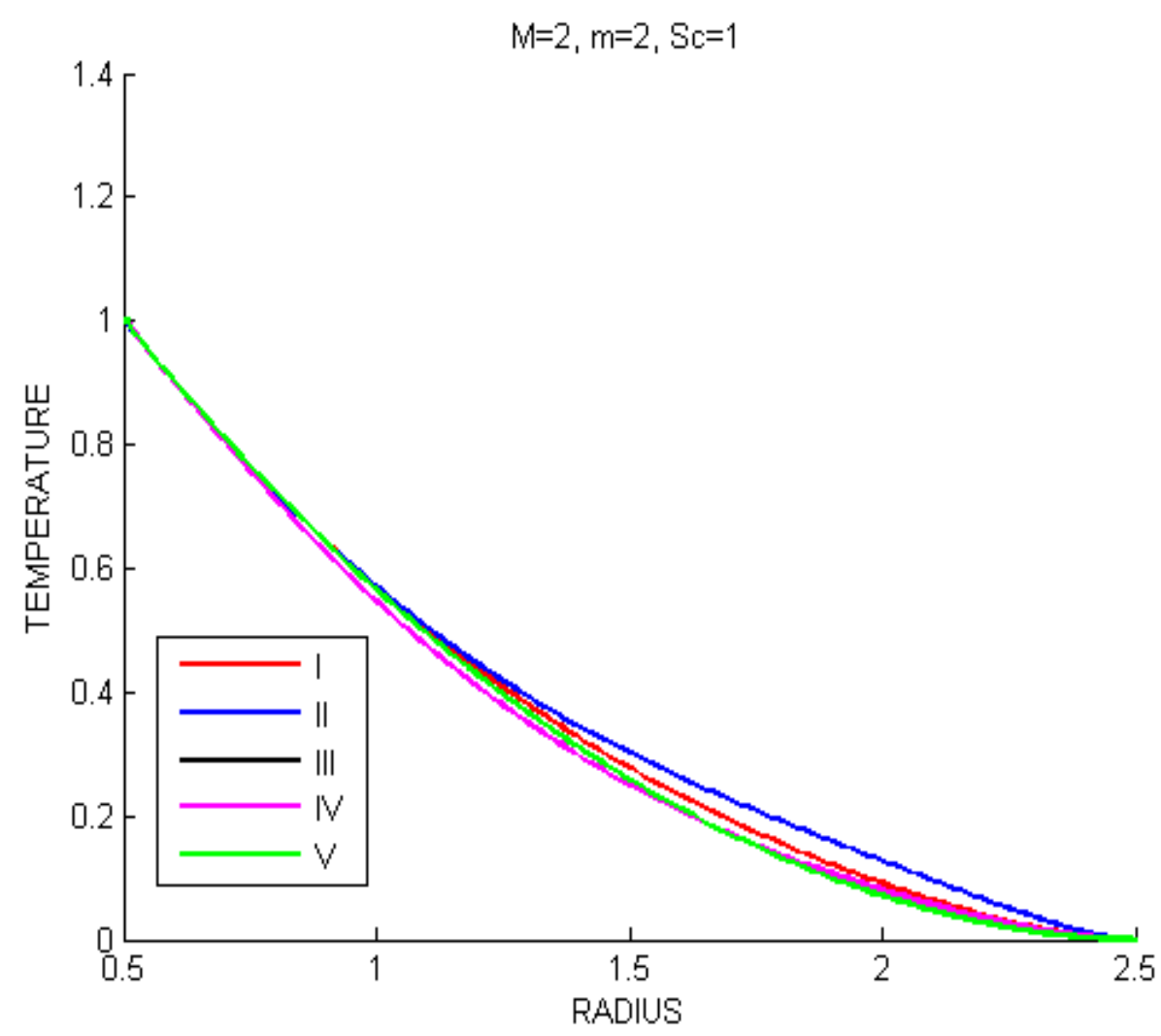

\begin{tabular}{|l|l|l|l|}
\hline & $\mathrm{t}$ & $\mathrm{Gr}$ & $\mathrm{Pr}$ \\
\hline $\mathrm{I}$ & 0.2 & $1.0 \mathrm{E} 4$ & 1 \\
\hline $\mathrm{II}$ & 0.4 & $1.0 \mathrm{E} 4$ & 1 \\
\hline $\mathrm{III}$ & 0.2 & $2.0 \mathrm{E} 5$ & 1 \\
\hline $\mathrm{IV}$ & 0.4 & $1.0 \mathrm{E} 4$ & 1 \\
\hline $\mathrm{V}$ & 0.2 & $1.0 \mathrm{E} 3$ & 10 \\
\hline
\end{tabular}

Figure 4 Temperature profiles

\section{CONCLUSION}

The magnetohydrodynamic turbulent free convection flow of a conducting fluid over a vertical infinite cylinder is numerically investigated. The effects of various flow parameters on the mean velocities and mean temperature were obtained. It is observed that increase in Grashof number led to increase in the primary velocity while there was no observable change with variation of Hall parameter. Variation of Prandtl number significantly varied the temperature profile while it had no observable effect on the velocity profiles. Secondary velocity profiles decreased with increase in Hall parameter while there was no observable variation in temperature profiles with variation in magnetic parameter and Hall parameter.

\section{REFERENCES}

[1] Davidson P., (2001) An Introduction to Magnetohydrodynamics, Cambridge University Press

[2] Ghadi Z. A., Goodarzian H., Gorji-Bandpy M. and Valipour M. S., (2012). Numerical investigation of magnetic effect on forced convection around two dimensional circular cylinder embedded in porous media. Engineering Applications of Computational Fluid Mechanics 6.3, $395-402$

[3] Holman, J. P., (2010) Heat transfer -10th ed. Mcgraw-Hill series in mechanical engineering.

[4] Kothandaraman C. P. and Rudramoorthy R. (2007). Fluid mechanics and Machinery, New Age International

[5] Mukuna W.O., Kwanza J.K., Sigey J.K. and Okello J.A. (2017). Analysis of heat and mass transfer rates of hydromagnetic turbulent fluid flow over an immersed infinite horizontal cylinder with Hall current. Journal of Mathematical theory and modelling.7(4), 45 - 64.

[6] Rhoads J. R., Edlund E. M. and Ji H. (2014). Effect of magnetic field on the turbulent wake of a cylinder in free-surface magnetohydrodynamic channel flow. Journal of Fluid Mechanics, 742, 446 -765

[7] Sarris E., Iatridis A. I., Dritselis C. D., and Vlachos N. S., (2010). Magnetic field effect on the cooling of a low-Pr fluid in a vertical cylinder, Physics of Fluids, 22, 98 - 113.

[8] Schlichting. H. And Gersten K., (2017). Boundary layer theory, Springer. 


\section{International Advanced Research Journal in Science, Engineering and Technology}

Vol. 8, Issue 5, May 2021

\section{DOI: $10.17148 /$ IARJSET.2021.8505}

[9] Vinuesa, R., Schlatter, P., Malm, J., Mavriplis, C. and Henningson, D. S. (2015). Direct numerical simulation of the flow around a wall-mounted square cylinder under various inflow conditions. Journal of Turbulence, 16, 555-587.

[10] Yoon H. S., Chun H. H., Ha M. Y., and Lee H. G., (2004) A numerical study on the fluid flow and heat transfer around a circular cylinder in an aligned magnetic field, International Journal of Heat and Mass Transfer, 47, 4075 - 4083.

\section{BIOGRAPHY}

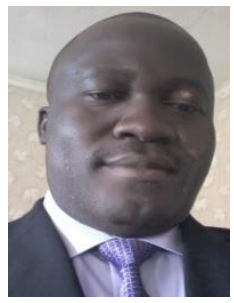

Wilys O. Mukuna was born in 1977 in Western Kenya. A Lecturer at the University of Kabianga, Department of Mathematics and Computer Science, he holds a Doctor of Philosophy degree in Applied Mathematics from Jomo Kenyatta University of Agriculture and Technology. Teaching both undergraduate and post graduate students his research interests are in the areas of Differential Equations, Fluid Dynamics and Magnetohydrodynamics. 